\title{
Production Technologies of Orchid Flowering Species
}

\author{
Sonam Dawa*, Tsewang Dolma, Tsering Angdus, Thinless Tharpa, \\ Tashi Stobgais and Tashi Angmo
}

National Research Institute for Sowa-Rigpa-Leh-Ladakh, (Ministry of AYUSH), India

*Corresponding author

\begin{tabular}{|c|}
\hline \\
\hline $\begin{array}{l}\text { Orchid, Symbiotic, } \\
\text { Himalaya, Fungus, } \\
\text { In vitro }\end{array}$ \\
\hline Article Info \\
\hline $\begin{array}{l}\text { Accepted: } \\
\text { 04 December } 2018 \\
\text { Available Online: } \\
\text { 10 January } 2019\end{array}$ \\
\hline
\end{tabular}

A B S T R A C T

India is recognized as a significant producer of orchids in the world. Nearly 1300 species of orchids are found in India which constitutes almost 10 percent of the world orchid flora with Himalayas as their main home (Medhi and Chakrabati, 2009). Orchids are amongst the most advanced flowering plants, highly specialized in many ways. They are distributed all over the world except the Antarctica (Ali and Mir, 2013). Orchid seeds are almost microscopic in size and almost 400 years ago, when orchid seeds were first seen and the development of a practical asymbiotic method for their germination by Knudson in 1921 . Thereafter, orchid growing and hybridization became widespread. Hybrids that early growers could not even have imagined became possible (Wing and Arditti, 2009). In vitro cultures of orchid seeds have shown that different species require different and often specific medium composition for optimum germination and growth. To overcome these problems some have suggested the development of optimized asymbiotic seed germination methods for entire genera or individual species. Asymbiotic orchid seed germination has been used for the production of commercially important orchids and has been shown to be an efficient tool for the production of orchids for conservation and reintroduction purposes (Kauth et al. 2006). In vitro seed germination studies can provide insights into in situ plant responses to environmental conditions and basic information of early plant growth and development. Symbiotic seed germination techniques represent an efficient way to promote the orchid fungus association under in vitro conditions and to study in vitro orchid-mycobiont specificity (Stewart and Kane, 2006).

\section{Introduction}

Orchids are the most fascinating and beautiful of all flowers. India is blessed with a wealth of orchid flora, and about 1300 species are estimated to occur in this country. In spite of their commercial value, the orchids in India have not yet gained the attention and popularity they reserve. The export and sale of orchids in India is negligible. Only few nurserymen based at Kalimpong in Darjeeling district of West Bengal and in Sikkim, export some orchids but the trade is unorganized.

Majority of the orchids known to cultivation are natives of tropical countries and occur in greatest diversity in humid tropical forests of South and Central America, Mexico, India, Sri 
Lanka, Burma, South China, Thailand, Malaysia, Philippines, New Guinea, Australia etc. Brazilian Cattleyas, Mexican Laelias and Indian Dendrobiums, Cymbidiums and Vandas have played a major role in the development of modern orchid industry.

Although a large number of species are native to India, attempts for orchid culture and its popularization is rather meagre. Only few nurseries in Darjeeling, Kalimpong and Sikkim cultivate orchids on commercial scale. Good collections of orchid species are being maintained at some institutions like Orchid Sanctuary, Kalimpong under the aegis of Bidhan Chandra Krishi Viswavidyalaya, Kalyani, West Bengal, Indian Institute of Horticultural Research, Bangalore; National Orchidaria at Shillong and Yercad under the Botanical Survey of India; Tropical Botanical Garden and Research Institute, Trivandrum; Orchid Research and Development Centre, Bhalukpong, Arunachal Pradesh. A herbarium of orchids is also being maintained at the Central National Herbarium in the Indian Botanical garden.

\begin{tabular}{|l|c|}
\hline Region & Genera \\
\hline Oceania & 50 to 70 \\
\hline North America & 20 to 26 \\
\hline Tropical America & 212 to 250 \\
\hline Tropical Asia & 260 to 300 \\
\hline Tropical Africa & 230 to 270 \\
\hline $\begin{array}{l}\text { Europe and Temperate } \\
\text { Asia }\end{array}$ & 40 to 60 \\
\hline
\end{tabular}

Source: wikipedia.org/wiki/orchidaceae

Orchids occur almost throughout the world, except perhaps in the Antarctica. Some species are found even in the frozen areas of Alaska, the snow covered areas of the Himalayas and the sandy deserts of Africa and Australia. However, orchids are abundant in tropical countries in South-East Asia, South and Central America and South America. India is very rich in orchid flora and the major areas are the eastern Himalayas, the Western and South Indian hills. There is tremendous scope for orchid improvement and development of industry based on these wonderful plants. Many orchids native to India have already proved to be important parent plants and contributed to the production of several outstanding hybrids in the world. Hybrids of certain Indian orchids like Vanda coeruela and species of Cymbidium, Dendrobium and Paphiopedilum are considered the monarchs in the orchid world. Due to the diversity of environmental condition in India, it is possible to grow all types of orchids in suitable places without the control of environment.

\section{The biology of orchid seed germination}

Orchid seeds are often referred to as "dust seeds", as they are tiny and contain few food reserves. In nature they may germinate but will not grow unless infected by a mycorrhizal fungus, which supplies the young plants with all the sugars and nutrients they need until the plants are large enough to produce food on their own. Once the seed has germinated it produces a fairly undifferentiated mass of cells called a protocorm. All being well this protocorm will continue to grow for many weeks, months or even years depending on species, until large enough to produce leaves and roots. In terrestrial orchids it is vitally important that the orchid/fungus relationship is maintained during the early stages of the plants life, as the protocorm is subterranean and cannot produce any food of its own. In epiphytic orchids the protocorms are often green, and thus can produce some food of their own. The orchid/fungus relationship has not been investigated in most tropical orchids.

\section{Aseptic culture}

Aseptic culture method is an elaborate process and is generally employed by commercial 
nursery men and orchid breeders. This is a very useful method for fast and large-scale multiplication of orchids. Seeds, meristems, leaf tips, stem segments, embryos, etc. all can be successfully cultured.

\section{Seed propagation}

Orchid seeds do not possess any stored food material or endosperms, and for their successful germination, it is necessary to protect them from fungal infection and also to supply food. There are two methods of seed culture (a) symbiotic and (b) asymbiotic. Both the methods are discussed in detail here.

\section{Symbiotic seed germination:}

This method is based on the principle that orchid seed requires fungal association for their germination. Following this discovery, a method was developed in which specific fungus was cultured first and then seeds were sown on it. Seeds were also cultured by inoculating the test tubes with both orchid seeds and fungi. The fungus grew by itself and encouraged the germination and good growth of, the seedlings. The relationship between orchid seed and fungus was found to be symbiotic. Most of the mycorhizal fungi of the orchids were identified as Rhizoctonia, the major species being $R$. repens, $R$. mucoroides and $R$. languinosa.

\section{Asymbiotic seed germination}

This method of seed culture involves germinating seeds and growing seedlings under aseptic conditions in an agar medium supplemented with nutrients required by the plant. Successful germination of Cattleya, Laelia. Epidendrum, Dendrubium and Oncidium seeds or agar medium containing sugar is possible. Inorganic salts, carbohydrates, organic substances like vitamins, amino acids, growth hormones, water and proper $\mathrm{pH}$ along with optimum light and temperature are necessary for success in germination. Numerous investigations were carried out to improve these media by supplementing with various carbohydrates, organic nitrogen sources, growth substances.

Low concentrations of nitrogen promoted seed germination and further growth of seedlings whereas high concentrations retarded these processes. Nitrates, ammonia and urea are well-utilized by orchid seeds. However, ammonium nitrate is the best nitrogen source for orchid seed germination and seedling growth. Certain growth substances also proved effective in enhancing the germination of seeds and subsequent growth of seedling. In majority of cases, auxins-IAA and NAA improved seed germination and seedling growth. Although, addition of gibberellic acid (GA) to the medium improved the growth of Cattleya seedlings compared to the control, but the percentage of germination was poor. In case of Dendrobium seeds, however, germination was promoted by using $\mathrm{GA}_{3}$ at 1 , 10 and 100 ppm.

\section{Propagation by tissue culture}

For a long time, the major means for propagating orchids clonally was the division of plants. Tissue culture methods for the quick propagation of orchids were introduced by several workers using various plant parts and a number of media. The techniques used have recently been commercially used on the propagation of orchid like Cymbidium, Cattleya, Odontoglossum, Phalaenopsis, Oncidium, Miltonia and Vanda. However suitable plant part, media hydrogen-ion concentration $(\mathrm{pH})$, light, temperature etc, have been found necessary for success.

\section{Basics of in vitro germination}

Symbiotic and asymbiotic seed germination

In in vitro germination the seeds are germinated in glass or plastic jars or dishes on 
an agar-based medium which contains all the sugars and minerals the seeds need to germinate and grow. There are two basic types of in vitro germination: symbiotic and asymbiotic. In symbiotic seed germination the seeds are sown with a small piece of an appropriate mycorrhizal fungus. This fungus then grows over the media, colonizes the germinating seeds and a symbiotic relationship is formed which presumably will sustain the protocorm until it produces leaves and becomes autotrophic. This technique is widely used for the propagation of temperate terrestrial orchids. It has the advantage that the media used is very simple (one of the most popular consisting of only powdered oats with a little yeast extract), and the resultant mycorrhizal plants are often stronger and more resistant to fungal infection than some of their asymbiotically propagated counterparts. It has the disadvantage that you need the correct strain of mycorrhizal fungus, or the symbiosis will not develop or might become parasitic and the seedlings die. Very little research has been carried out on the mycorrhizal fungi of tropical orchids, and so the appropriate mycorrhizal fungi are not at this time readily available (Vij and Pathak, 1989).

Asymbiotic germination is commonly used in the propagation of tropical orchids, which tend to be easier to grow than their temperate relatives. The media used for asymbiotic germination is more complex than that for symbiotic germination, as all organic and inorganic nutrients and sugars must be in a form readily available to the orchid without the fungus intermediary. Should fungi become available from in situ sowings at a later date, then it might also be possible to use symbiotic techniques.

\section{Basics of maintaining sterile conditions}

In both symbiotic and asymbiotic germination, it is vital that all media, jars, instruments and seeds are kept sterile at every stage of the germination procedure. Any bacteria or fungi to get into the jars will grow much quicker than the seedlings and will soon out. Sterile conditions are created in the preparation of the media by autoclaving all media and jars to be used for 15 minutes at 15 atm. This temperature and pressure is sufficient to kill all bacteria and fungal spores in the media. The seeds must be sterilized and transferred to the jars without introducing extraneous bacteria or fungi.

This is usually done by sowing from surfacesterilized green capsules, or by sterilizing mature seeds with sodium or calcium hypochlorite, or hydrogen peroxide, and ensuring that all instruments used in the transfer are sterile. With a little care and practice sterile conditions can be created and maintained from germination to the planting out of the seedlings. Sterile conditions for pouring the media and sowing the seeds are obtained grow and kill the germinating seeds.

\section{Use of the laminar air-flow bench}

There are some basic rules to be observed in using the laminar air-flow bench.

1. Always sterilize thoroughly before use with 70-90\% alcohol (ethanol) preferably: be very careful if using "alcohol" which also contains methanol. Methanol is toxic and can cause blindness if swallowed. Use the spray and swab down all surfaces in the cabinet with cotton wool soaked in alcohol (walls and ceiling too). Sterilize both before and after switching on the cabinet. Be careful not to breathe in ethanol when using spray when the cabinet is switched on.

2. Everything which goes into the cabinet should be sterile or sterilized. Wear gloves, and sterilize them thoroughly before use by putting them on, spraying with alcohol and holding them in the cabinet until the alcohol 
has dried. It is possible with practice, instead of wearing gloves, to wash the hands and scrub the nails thoroughly using anti/bacterial soap, dry and sterilize with alcohol as before, but should there be any problems with bacterial contamination, revert to gloves. Wear a lab-coat, and clean it regularly. Make sure glassware is clean. Glassware etc. can be sprayed with alcohol on entering the cabinet and any marks made with marker pen on the glass will come off if sprayed with ethanol. If the glassware is clean, spraying with ethanol may not be necessary. Instruments can be autoclaved before use either wrapped in aluminium foil or in brown paper sealed with masking tape. Once in the cabinet sterility is ensured by dipping in $100 \%$ ethanol and flaming three times before use.

3. The ethanol is best kept in a tall glass jar to allow maximum exposure of the instruments to the ethanol. After flaming the instruments are quickly placed on the top of a sterilized glass. Remember that any bacteria or fungal spores in the cabinet will float down and towards you in the flow. Never place hands, sleeves or anything else above or beyond anything sterile (e.g. media). Keep movements smooth and avoid creating air turbulence which could bring in contamination. Do not talk, cough or sneeze in the cabinet. Work towards the back of the cabinet as much as possible, and minimize exposure time of media where possible.

4. Maintain sterile conditions by swabbing bench regularly with alcohol, resterilizing instruments after each use and resterilizing hands after they have been in contact with anything outside the cabinet. Especially, do not touch face or hair with gloves on.

\section{Preparation of the media}

\section{Introduction to media preparation}

Media can be prepared either from the basic ingredients (Thompson, 1977) or bought in powder form from a supplier. There are many different media available commercially and many others devised by amateurs and professionals alike to grow certain species. When attempting to germinate a new species if possible it is good to try with a few different media at both full and half strength, in order to determine what is best for that species. Masdevallias for instance are known to be "picky" about which media they will germinate on (Richard Warren) $\mathrm{pH}$ is also important. Most orchids will germinate on media of $\mathrm{pH} 5.5$, but Andean species may favour slightly higher $\mathrm{pH}$ e.g. 5.6 to 5.9 (Monica de Navaho). Remember when experimenting with $\mathrm{pH}$ that the $\mathrm{pH}$ of the media after the addition of agar will be higher than before the addition of agar (Murashige, 1978).

Commercial preparations of Phytamax (Sigma Chemicals, Aldrich, England) and Murashige and Skoog have been the main media used in the project. Either of these media can be prepared either half strength or full strength (half strength recommended for Murashige and Skoog).

The general method preparation of these media is as follows.

\section{General method for preparation of media}

Measure out the correct quantity of media powder into 11 bottle, taking care to avoid the dust.

MS only: add correct quantity of sugar and $2 \mathrm{~g} / \mathrm{l}$ activated charcoal

Add magnetic stirrer and a small quantity of distilled water and stir until dissolved

Make up to 1litre using distilled water, stirring continuously

Measure the $\mathrm{pH}$ and adjust to 5.6 using $\mathrm{HCl}$ or $\mathrm{NaOH}$, stirring throughout with the magnetic stirrer. ${ }^{*}$ Caution - if a $\mathrm{pH}$ meter is used then do not stir using the element: the membrane is 
very delicate and expensive and could easily break. If a $\mathrm{pH}$ meter is not available then $\mathrm{pH}$ papers are sufficient.

Pour half of the liquid into a flask, add $4 \mathrm{~g}$ agar to each vessel ( $8 \mathrm{~g} / \mathrm{l}$ agar) and stir to disperse

Screw the lid loosely on the bottle; cover the tops of flasks with aluminium foil and autoclave. In ideal conditions the media should be made in one bottle and the magnetic stirrer kept in the bottle throughout autoclaving so that the media can be stirred before pouring, thus making a more even distribution of charcoal etc. throughout the jars. However, for safety reasons the University prefers that two $500 \mathrm{ml}$ bottles or flasks are used so keep the magnetic stirrer in the bottle and swirl the flask gently before poring to disperse the charcoal.

\section{Pouring of media}

The media must be poured into sterile jars or petri dishes, using the laminar air flow bench. Jars must be thoroughly washed and rinsed four times before use, and sterilized for 15 minutes at 15 p.s.i. in an autoclave. If lids are used on the jars, remember to screw them on loosely before autoclaving. If not lids are available then coverings can be made by wrapping placing a piece of aluminium foil over the mouth of the jar and sealing tightly with a twist of the wrist (Murashige, 1974). Heavy-duty brown paper tied with string can also be used, but is more cumbersome. Resterilize any jars which come out of the autoclave with a hole in the foil, or the foil lid coming off.

1. Wait for media to cool enough to handle comfortably. When the agar appears less fluid and the bottle or flask can be handled easily, it is ready to pour. Agar poured while still very hot will create a lot of condensation.

2. Line the jars or petri dishes up at the back of the laminar air flow bench. Loosen lids of jars.

3. Open jar lids or petri dish lid and pour, moving left to right (if right handed) to avoid any part of the hand or lab coat hovering over an open jar or dish.

4. Leave to set, and then replace lids. Lids can be closed immediately after the media is poured, but this leads to condensation in the jars. Some free water in the jars may or may not be desirable, depending on whether seed is being sown from green capsules or mature seed.

The preparation of media, from the mixing of the ingredients to the setting of the poured media, takes roughly 4 hours. If 21 of medium has been made at the same time then a hot plate can be used to keep one bottle of media warm while the other is setting. A hot plate should only be used as a short term emergency measure; however, as longer term use (e.g. half an hour) can cause the charcoal to precipitate out.

\section{Sowing the seed}

\section{Seed collection and storage}

Seeds can be collected either in green capsules or as mature seed. A green capsule is judged to be mature and ready for sowing when it looks full and 'gives' a little when gently pressed. Capsules can be stored for a few weeks wrapped in kitchen paper, in a well aerated part of a domestic refrigerator (e.g. cheese compartment).

Do not store in plastic bags or the capsules will sweat and rot. If at all possible, try to collect capsules which have already dehisced on a dry day. Ideally seed should be used fresh or dried over a saturated solution of calcium hexahydrate (Seaton et al., 2015). If that is not available seeds can be dried over calcium chloride, silica gel (harsher than calcium chloride and really only recommended for 
short-term use) or simply left to dry at room temperature (dry climates only). Once dried the seeds can be stored for many months in air-tight vials in a refrigerator $\left(4-5{ }^{\circ} \mathrm{C}\right)$. Again, seed should never be stored or transported in plastic bags or air-tight containers (Mitra, 1971).

Times from flowering to seed maturity vary greatly between species and sites, for example it takes roughly 3.5 months for seeds of Epidendrum or Masdevallia to ripen and roughly 18 months for Odontoglossum. Conventional estimates do not take account of different climatic conditions; obviously a capsule grown in a warm glasshouse will ripen much quicker than one growing in a cloud forest.

\section{Seed sowing}

\section{Green capsules vs. dry seed}

Seeds can be sown from capsules either before dehiscence ('green capsules') or after dehiscence ('dry seed'). The advantages and disadvantages of using green capsules or dry seeds are as follows.

\section{Sowing from green capsules}

The inside of an orchid capsule, if intact, is naturally sterile. Therefore if you sterilize the outside of the capsule, where bacteria and fungi can collect, and cut open the capsule under sterile conditions then the seeds should be sterile. This method has the advantage that the seeds themselves do not need to be sterilized (which can sometimes lead to damage). In addition, some seeds, if taken from capsules which are almost ripe, germinate quicker than those taken from mature capsules as the dormancy mechanisms are not yet in place. It has the disadvantage that once opened all the seeds from an immature capsule must be sown or discarded (some mature seeds may be dried and saved).
In addition, seeds sown from capsules which are not sufficiently mature may germinate very slowly or not at all.

\section{Sowing from dry seeds}

Once a seed capsule has opened the seeds are no longer sterile. The seeds thus need to be sterilized, usually using a solution of sodium hypochlorite (bleach), calcium hypochlorite or hydrogen peroxide. The seeds are shaken in a solution of sterilant containing a drop of detergent to 'wet' the seeds, then rinsed in sterile water and planted on to the medium. This method has the advantage that seeds can be collected, air-dried, stored for many months in the fridge and used when needed. It must be remembered that at times availability of seed in either form will govern what is sown.

\section{Sowing from green capsules}

The general method from sowing from green capsules is as follows

Using a scalpel, carefully trim the dead flower off the capsule

Using a soft toothbrush gently scrub the capsule with soap solution

Rinse the capsule in water

Immerse for 10 minutes in $1 \%$ sodium hypochlorite (bleach solution) to which a drop of detergent has been added.

Transfer capsule in bleach solution to the laminar air-flow cabinet.

Pick capsule out of bleach solution using forceps, preferably holding on to what is left of the stalk. Dip in $100 \%$ alcohol and pass briefly through the flame. Allow alcohol to burn off and capsule and forceps to cool. Repeat twice for larger capsules. Use your own discretion as to how many times to flame for small or delicate capsules (perhaps only once). If not possible to hold by the stalk, change the position of the forceps before flaming again.

Transfer to a sterile cutting surface (e.g. 
sterilized petri dish). Using a sterile scalpel slice the capsule in half longitudinally. Use a fresh blade for each new capsule to prevent the spread of any viruses.

Lift one half of the capsule using forceps and gently tap over the media to sow seeds

Repeat until all loose seed is used up. Less mature seed can be teased out of the capsule using forceps

A few drops of water are normally added to each jar, and any clumps of seeds broken up and spread out a little over the agar.

\section{Sowing from dehisced capsules (dry seed)}

There are several different methods of sowing from dry seed. All rely on sterilization of the seed, and rinsing in sterile water before sowing, but techniques vary. Sterilization times also vary depending on the species, time after dehiscence when the seed was collected, climatic conditions at the time of collection and methods of drying and storage. A range of sterilization times is therefore recommended for new seeds.

The two main techniques are used for sowing mature seeds: the syringe technique and the packet technique. Other techniques are possible (e.g. filtration technique using a Buchner funnel). In both the syringe and the packet techniques all instruments and water needed for the sowing is best sterilized the day before needed as it takes a long time for the water to cool down after autoclaving. In general, the syringe technique is used for most sowings and the more cumbersome packet technique used for very small or rare seeds.

\section{Syringe technique}

Take a $5 \mathrm{ml}$ syringe, plug the tip of the syringe with cotton wool wrapped in a piece of cloth cut from a pair of tights, replace the plunger and autoclave. At the same time autoclave a supply of distilled water (in jars or bottles) and forceps.

Pull out plunger and pour a small quantity of seed into syringe. (Large numbers of seeds will form a crust-like mass if technique $5 \mathrm{~b}$ is used to sow, making it difficult to sow thinly). Replace plunger.

Draw $4 \mathrm{ml}$ of $1 \%$ bleach solution (to which one drop of detergent has been added) into the syringe. Agitate for 5 minutes (or other sterilization time), making sure that the seeds are bathed in the solution and not trapped in air bubbles. Eject solution and draw in fresh solution. Agitate for another 5 minutes, and then eject bleach.

Rinse seeds 3 - 4 times by drawing in sterile distilled water, agitating briefly then ejecting.

Sow seeds either by a) sterilizing the neck of syringe and pouring the seeds onto the medium. Remove any excess water or b) expelling all excess water, removing the cotton wool ball using forceps and dabbing seed on to medium.

\section{Packet technique}

Create a packet out of a piece of paper

Sow a small quantity of seed into the packets. Again, large numbers of seed will clump and hinder penetration of the bleach.

Fold and seal using a stapler. Immerse in distilled water for 5-10 minutes, squeezing gently to dispel any air bubbles.

Transfer packet using forceps to $1 \%$ bleach solution to which one drop of detergent has been added. Leave for 10 minutes (or other sterilization time), stirring or agitating frequently.

Transfer packet plus bleach to laminar flow cabinet. Using forceps transfer packet to sterile distilled water (in a jam jar). Agitate. Repeat 3 - 4 times to rinse seeds.

Gently squeeze out excess water and transfer to sterile surface. Using sterile scissors cut open packet, and sow seeds by dabbing onto medium. Normally using this technique the packets are put in a container of bleach over a 
magnetic stirrer. The theory is that the staples will act as magnetic fleas and stir the packets automatically. Merely stirring or agitating frequently does the same job, and several packets can be immersed in bleach at the same time to speed up the sowing process.

\section{Capping the jars}

Once sown the jars can be capped either using cling-film or cellophane covering cut from bags use to cook chickens in the oven. With cling film the film must be unwrapped in the flow cabinet, doubled over and the side closest to the back of the cabinet placed over the jars. The cling film is then secured with an elastic band and surplus film trimmed off.

The cellophane is cut into squares, and autoclaved in jars before being used. A square of cellophane is removed from the jars using forceps, placed over a jar of medium and secured using an elastic band. The cellophane is easier to handle than the cling-film and is reusable. It is therefore recommended as the preferred capping material.

\section{Care of seedlings}

\section{Seedlings in flasks}

The seedlings at USFQ are grown $40 \mathrm{~cm}$ under 20 Watt fluorescent tubes in a growth room set at $18{ }^{\circ} \mathrm{C}$ with 16 hours light and 8 hours dark. Newly sown flasks should be checked for contamination as often as possible after sowing. If contamination is caught early enough, it can often be cut out before it has had the chance to spread. Once a fungus has formed spores however, or if there is spare liquid in the bottom of the flask, cutting out the visible contamination will do no good. In most cases such as this, the flask should be discarded. Occasionally a fungal contaminant will actually aid germination (Monica de Navarro, pers. comm).
In those cases the seedlings can be left to grow, but must be transplanted before the fungus takes over and kills the seedlings. Sterile water can be added if the jars look dry, using a sterilized syringe. Seedlings are first transferred when the leaves have formed and the jars begin to look crowded. The exception to this rule is if it is more efficacious to remove protocorms from a contaminated jar or petri dish, rather than cut out the infection.

Seedlings are transferred using sterile forceps to fresh jars of media. A crochet hook can be useful at this stage to remove delicate seedlings. The next medium can be the same as the first, but it is often better to add complex substances to the media to encourage root development (e.g. mashed banana, coconut milk, pineapple juice or vitamin B. A small hole can be put in caps (if metal or plastic, possibly if cellophane, not if clingfilm) and sealed two or three times with the micropore to provide a spore-proof breathable surface in the cap. The holes made should not be more than $2 \mathrm{~mm}$ in diameter. Several transfers will have to take place before the seedlings are ready for potting up.

\section{Planting out}

Seedlings grown in jars have been in a very cosseted environment and must gradually accustomed to their new environment before planted into pots. In the growth room light is low and both light and temperature fairly constant. The humidity in the jars is high and the seedlings are protected from the attacks of fungi, bacteria and herbivores. In the field both light and temperature will vary greatly. In particular the new seedlings need to be protected from strong sunlight: even a small amount will burn the leaves of what are essentially shade-grown plants. The new seedlings, having been raised in conditions of high humidity, will have poor cuticles, and thus the seedlings need to be gradually 
accustomed to a drier atmosphere before planting. Finally, both in the acclimatization stage and the newly-planted stage all seedlings must have daily attention to check for problems, more than daily if the weather is dry and sunny.

The following are guidelines to planting out:

1.Start the planting out process at the beginning of the wet season if possible. The lower amounts of light and high humidity at this time should make it easier for the seeds to acclimatize and establish.

2. Put the jars in a shaded position, sheltered from rain, to acclimatize to the new light and temperature conditions. Leave for 2-4 weeks with the lids on.

3. Loosen the jars lids to let in a small amount of air. Leave for about a week. Check daily for any leaf shrivelling and make sure media is moist but not wet.

4. Open a little more. Leave for a few days, checking daily.

5. Half open the lids. Leave for a few days, checking daily

6. Open the lids to three-quarters. Leave for a few days, checking daily

7. Fully open the jars. If possible leave for about a week before transporting the seedlings to the nursery for transplanting.

8. Choose the correct potting medium for the seedlings.

9. Carefully remove the seedlings from the jar, tease apart gently and wash off all traces of agar

10. Fill a pot with potting compost and put it in a basin of water. Dip the roots of the seedling in fungicide and plant the seedling into the floating medium

11. When the pot is removed from the water the medium should stick to the roots of the orchids without damaging them. Place the newly planted seedlings into a propagator or small table 'tent' made from clear plastic to ensure high humidity during the establishment phase. Water regularly from the top avoiding the leaves and never leave standing in water. Some spraying with water could be helpful in the early stages to maintain high humidity.

12. Again, gradually acclimatize the seedlings to their new environment (e.g. fully sealed tent, tent door partially opened, tent door fully opened, no tent but protected from rain, no protection from rain, or should all plants be kept sheltered under a plastic cover) When fully acclimatized and large enough to be potted up, they can either be transplanted into larger pots or simply tied onto a tree trunk, branch or piece of bark. Spray with water in the early stages of development- develop judgement on how much and when as water addition needs to be enough to keep the plant from drying up but not so much that it encourages fungal rot.

\section{Cultivation}

Cultivation of orchids involves different aspects as described below.

\section{Orchid house}

An orchid house is a protecting structure that provides suitable environment for the successful cultivation of different kinds of orchids. Many types of structure have been used over the years and the simplest ones are those used in warm regions. Orchid house should be located in an open site where sufficient light is available throughout the day. It should be built lengthwise in north-south direction. The floor of the house should be slightly higher than ground level for better drainage.

\section{Lath house}

Inclined or flat roof orchid house supported by wooden posts embedded in a concrete base is particularly suitable for growing tropical orchids. The roof of such houses is made of 
split bamboo or wooden slates sometimes covered with polythene films in heavy rainfall regions. The sides may be kept open or covered with wire mesh. The floor of the house should be covered with paved bricks, porous gravels, pumica, cinder or similar absorbent material so that high humidity can be maintained inside the houses. In the western side, growing of climbers like Impomea, Passiflore etc, over the roof is advantageous. In the center of there should be small tanks for water. Pipeline inside the house or spray system is necessary for watering the plants. Proper light, temperature and humidity should be maintained according to the requirements of orchids cultivated inside the house.

\section{Fibreglass house}

This is an improved type of house with the fibre glass roofing, providing uniform mild and diffused sunlight to the orchids. This is generally provided with short walls over which glass windows are fixed all-around. Heaters may also be provided inside, if necessary. The floor of the house should be covered with the absorbent material. There should be water spray system inside to maintain humidity and give a cool effect in tropical zone. Hard wooden benches consisting of 2-3 tiers should be provided all along the inner wall and in the middle of the house. Advantages of this kind of orchid houses over the lath houses are durability, cleaner environments, controlled watering, diffused sunlight and suitability in both tropical and subtropical zones.

\section{Controlled glasshouse}

They have either a heating system designed for tropical orchids to cultivated in temperate conditions or air cool sys- tem designed for temperate orchids in tropical zone. The house may be built with walls about $106 \mathrm{~m}$ high on either side with a door at one or both ends and a roof pitching from the walls at approximately $45^{\circ}$, the roof being constructed entirely of glass. This kind of orchid house is provided with exhaust fans and ventilators to be used when required. During summer proper shade is provided by suitable material.

The use of passive solar principles (wood construction, double glazing, insulated north and east wall) showed advantages in cold climates over traditional designs. Houses with controlled environment are very useful for growing exotic orchids. It is also helpful in regulating the flower production. Cybidium, Paphiopeilum, Cattleya, Miltonia etc. are suitably cultivated in such houses.

\section{Selection of plants}

A careful selection of proper species and hybrids is necessary for the successful cultivation of orchids. There are many beautiful commercial orchids belonging to different climatic zones and all of them cannot be grown in a particular climatic condition. Therefore, choice of orchids depends upon the climatic conditions of the place where they are to be grown. Further, orchids should be so chosen that one gets flowers throughout the year. Plants selected should be healthy and free from pests and diseases. Assessment of species and hybrids for their performance in a particular area and selection of promising ones are very important for the commercial exploitable orchids.

\section{Containers}

Clay pots, wooden or galvanized wire baskets, tree fern blocks, logs of wood, etc. are the different types of containers used for growing orchids. Porous earthen pots with holes on their sides and bottom are the best receptacles for growing orchids. For a few pseudo bulbous orchids teak wood baskets should be made to 
hang them from rafters etc. The upper part of the pot should be well packed with a mixture of smaller material in the proportion of 5 parts of broken bricks and part of fern fibre, the top layer of even smaller pieces is advisable. Orchids should be fixed firmly to their pots with coconut strings or copper wire, if necessary, by a strong stake of durable wood.

Coconut shells can be split into halves, bored and used as containers. In recent years, plastic containers are becoming very popular. Plastic pots are light in weight, easy to transport and do not accumulate algae or salts on their sides. Besides, they retain moisture longer than clay pots.

\section{Potting media}

When orchids are to be cultivated in unnatural environment, they are put in several suitable growing media which supply water and nutrients to the roots and at the same time provide good drainage and aeration. In many of the tropical countries orchids have successfully been grown in coconut husk and pieces of brick and charcoal. Under natural conditions terrestrial orchids are found growing in forest soils composed of rich humus accumulated from the falling leaves over a period of time. For a potting medium simulating this natural humus, a mixture of equal parts of leaf mould, garden soil and coarse rivers and will be suitable. In fact any well drained potting mixtures containing $50 \%$ or more organic matter can be used. Successful orchid growing depends not only compost but on other factors, viz. rainfall, temperature, watering, compost, light, shade, moisture and humidity, etc.

Sphagnum moss is not good for the plains of India where it soon rots and turns slimy. Fern roots of Osmunda, Polypodium (birds nest fern) are cut and dried thoroughly in the sun and then beaten to separate the fibre and used.
Leaf-mould rapidly deteriorates in the tropics and produces fungal diseases and so it should be discarded, if possible. The fibrous roots of Polypodium provide an excellent potting material for orchids. Sphagnum moss, especially the living portion, is the most useful kind of moss for orchids as they root readily in it.

Phalaenopsis and other plants when fixed to living trees such as mango and other fruit trees grow very satisfactorily. Coconut husks are used for growing Phalaenopsis. Terrestrial orchids such as Calanthes, Phaius etc. do well in a mixture of leaf mould and a little dry cow dung charred if possible. Perfect drainage and keeping the plants on the dry side after flowering must be given attention.

\section{Potting and re-potting}

Potting orchids is an important item of work and the knowledge of growth and flowering behavior of plants is very essential to perform such operation. As a general rule, the period soon after the flowering season is the best for potting or repotting orchids. They should not be disturbed during flowering or at dormant stage. Care should also be taken that pots and all to be used in potting are perfectly clean. Crocks (earthen pots) should thoroughly be washed and dried before use. These will minimize the spread of diseases. The amount of crocks to be used varies from about onethird the depth of the pot in Paphiopedilum, Cymbidium, Phauis and other terrestrial orchids to a greater depth in epiphytic orchids. It also depends on the type of potting material. When osmunda fibre or other porous materials are used, the quantity of crocks will be less.

Whatever material is used, the ingredients of the media should be mixed in suitable proportion. It should be heaped in the pot making a small mound on the top. The plant to be potted is placed on the top of this mound 
with the roots spread outwards and downwards along the slopes of the mound. Holding the plant in place with one hand, the space between the roots and wall of the pot is filled with more medium, till the pot is filled to an inch from the rim of the pot and packed properly. The medium should cover only the roots and the rhizome, but never the pseudobulbs. While potting Dendrobium and Vandaceous orchids, care should be taken so that the aerial roots are not buried inside the compost. The taller orchids might need a support, and therefore, a stake is provided with and the plant loosely tied to it.

Plants should be repotted when it has entered into a stage of active vegetative growth. While repotting, the whole plant is taken out of the pot without causing any root damage. Dead back bulbs and roots are cut away, and each portion is potted in a fresh pot.

Spring is the best time to undertake any repotting when the new growths are getting under way and the new roots soon to be made can penetrate immediately into the fresh compost. Orchids like Cymbidium react favourably when repotted every other year or so. Pleone, Calanthe, Thunia, Phaius etc. need annual repotting. Vandaceous orchids tolerate very little disturbance and Paphiopedilum species \& should not be repotted unless it is absolutely necessary.

\section{Manuring and fertilization}

The major mineral elements required in large amount are nitrogen, phosphorus, potassium, calcium, sulphur and magnesium. Iron, boron, copper, manganese, molybdenum, zinc and other micronutrients are also necessary but in of the commercial growers employ some form of overhead watering in their green houses. They may alter their watering procedure at certain times of the year because of cut flower production. There are several form of the extremely small quantity. Under natural condition orchids get their necessary inorganic nutrients from the soil or decayed organic matter on the bark upon which they are growing and also from the atmosphere washed down by rain. The organic matters are supplied by the decaying vegetable and animal debris. When under cultivation all these nutrients should be supplied to the orchids regularly for their growth and flowering.

\section{Inorganic fertilizer}

A combination of NPK in the ratio 10:12:10 was found the best for growth and flowering of a large number of species and hybrids suitable for growing under warm humid conditions. The plants of Aranda wendy scott should be fed on a 10 day round with a solution containing $72 \mathrm{mg}$ each of $\mathrm{N}$ and $\mathrm{P}$ and $36 \mathrm{mg}$ of potassium.

\section{Organic manure}

Fresh as well as dry cow dung, sheep, chicken, pig or fish manure, dried leaves, oil-cakes, bone meal are some of the common manures used for feeding orchid plants.

Dried cow dung dried leaves and bone meal are sometimes mixed in the medium while potting. Dried chicken manure @ 100 g/plant in Dendrobium and $50 \mathrm{~g} / \mathrm{plant}$ every three months, increased flower yield in Dendrobium and increased inflorescence length and flowers per spray in both orchids.

\section{Watering}

Orchids like spray of water, unlike other plants which are watered by pouring. Majority overhead system but there are usually some modifications of two basic types either a stationary mist head or oscillating sprinkler type.

Like other flower crops, orchids should be 
watered thoroughly, and until the surface of the potting mixture begins to dry, further watering should not be done. The frequency of watering depends on several factors such as climatic conditions, type of growing medium, type and size of container, growth habit of orchid, etc.

Table.1

\begin{tabular}{|l|c|l|c|}
\hline Orchids genera & $\begin{array}{c}\text { Time to maturity } \\
\text { (months) }\end{array}$ & Orchid genera & Time to maturity (months) \\
\hline Bulbophyllum & 3 & Laelia & 9 \\
\hline Brassia & 9 & Masdevallia & 3.5 \\
\hline Calanthe & 4 & Miltonia & 9 \\
\hline Catasetum & 10 & Odontoglossum & 7 \\
\hline Cattleya & 11 & Oncidium & 9 \\
\hline Cymbidium & 10 & Paphiopedilum & 10 \\
\hline Cypripedium & 3.5 & Phaius & 7.5 \\
\hline Coelogyne & 13 & Phalaenopsis & 6 \\
\hline Dendrobium & 12 & Spathoglottis & 1.5 \\
\hline Encyclia & 8 & Stanhopea & 7 \\
\hline Epidendrum & 3.5 & Vanda & 20 \\
\hline Sorian & & \\
\hline
\end{tabular}

Source: www.phytotechlab.com

In conclusion

- With in vitro germination large numbers of seedlings can be raised in a relatively short time. Each orchid capsule contains many thousands of seeds, so there will be plenty of plants to go round.

- Symbiotic seed germination with a mycorrhizal fungus may also increase seed germination and long-term survival of seedlings.

- The growing of orchid seed with the help of culture media has revolutionized the commercial orchid growing and hybridization, as every viable seed can be turned into a new plant. This has put orchid growing on par with other commercial greenhouse crops.

Cost efficient protocols for mass propagation of rare, threatened and endangered orchids, new hybrids, as well as transgenic orchids have to be developed further in order to commercialize and conserve them.

\section{References}

Ali, A. and Mir, A. 2013. A review on orchids in India and their conservation. International Journal of Advanced Research 1(2):5-7.

Kauth, P.J., Vendrame, W.A. and Kane, M.E. 2006. In vitro seed culture and seedling development of Calopogon tuberosus. Plant Cell, Tissue and Organ Culture 85: 91-102.

Langhans, R.W., Horst, R.K. and Earle, E.D. 1977. Disease-free plants via tissue culture propagation. HortScience 12: 149-150

Medhi, R.P. and Chakrabarti, S. 2009. Traditional knowledge of NE. People on Conservation of wild Orchids Indian. Journal of Traditional knowledge 8: 11-16.

Mitra, G.C. 1971. Studies of seeds, shoot-tips $\&$ stem disks of an orchid grown in aseptic culture. Indian Journal of Experimental Biology 9: 79-85.

Murashige, T. 1974. Plant propagation 
through tissue culture. Annual Reviews of Plant Physiology 25: 135166.

Murashige, T. 1978. Plant tissue culture: History, current status and prospects. Tissue Culture Association Report 12: 41-47.

Rogerson, W.P. 1991. Hybridization of white Paphiopedilums, Part I American Orchid Society Bulletin 60(7): 673682.

Seaton, P.T., Pritchard, H.W. and Marks, T.R. 2015. Aspects of orchid conservation: seed and pollen storage and their value in re-introduction projects. Universal Journal of Plant Sciences 3(4): 72-76.
Stewart, S. L. and Kane, M. E. 2006. Symbiotic seed germination of Habenaria macroceratitis (Orchidaceae), a rare Florida terrestrial orchid. Plant Cell, Tissue and Organ Culture 86:159-167.

Vij, S.P. and Pathak, P. 1989. Micropropagation of Dendrobium chrysanthum Wall. through pseudobulb segments. Journal of the Orchid Society of India 3: 25-28.

Wing, Y. T. and Arditti, J. 2009. History of orchid propagation: a mirror of the history of biotechnology. Plant Biotechnology Reports 3:1-56.

\section{How to cite this article:}

Sonam Dawa, Tsewang Dolma, Tsering Angdus, Thinless Tharpa, Tashi Stobgais and Tashi Angmo. 2019. Production Technologies of Orchid Flowering Species. Int.J.Curr.Microbiol.App.Sci. 8(01): 147-161. doi: https://doi.org/10.20546/ijcmas.2019.801.018 